\title{
RETRATOS E SIMULACROS MACHADIANOS: UMA LEITURA DE ENQUANTO ISSO EM DOM CASMURRO
}

\author{
Naira de A. Nascimento*
}

$\mathrm{H}$ á pouco mais de vinte anos, Leyla Perrone-Moisés diagnosticou a críticaescritura como um novo estágio nos estudos literários. ${ }^{1}$ Tinha ela em mente a descrição de uma nova forma de abordagem do objeto literário que, através do seu discurso, apagasse as barreiras entre a prática e a crítica. Louvado ou apedrejado, o certo é que o pós-estruturalismo francês estabeleceu um marco nos estudos literários, abalando muitas certezas. Outras certezas também foram silenciadas no campo da história, que acabaram por propiciar um dinamismo fecundo no estudo das relações entre a literatura e a história. A ficção contemporânea não poderia estar alheia a este cenário de mudanças de paradigmas. Aliás, a literatura nunca esteve. $\mathrm{O}$ que nas últimas décadas ela acusa mais fortemente é a intensidade com que se volta para o próprio processo produtivo, não descurando, contudo, do olhar crítico ao universo em que se insere. No dizer de Linda Hutcheon, para quem a estética pós-moderna assume vasto significado:

* Universidade Federal do Paraná.

1 PERRONE-MOISÉS, Leyla. Texto, crítica e escritura. São Paulo: Ática, 1978. 
As formas de arte têm demonstrado cada vez mais que desconfiam da crítica exterior, a ponto de procurarem incorporar o comentário crítico dentro das suas próprias estruturas, numa espécie de autolegitimação que curto-circuita o diálogo crítico normal. ${ }^{2}$

Mesmo quando elege o passado como cenário, e talvez aí mais claramente, essa produção não se poupa de questionar "para onde caminhamos?" Metaficção historiográfica ${ }^{3}$ ou novo romance histórico ${ }^{4}$ se apresentam como propostas de nomenclatura para isolar esse novo corpus. Ou melhor, isolar parece-nos categórico demais porque o que, de forma mais evidente, se revela nessas obras ficcionais são as teias problemáticas que ela premeditadamente espalha a sua volta. É o que nos apresenta Enquanto isso em Dom Casmurro, ${ }^{5}$ romance de José Endoença Martins.

A recuperação do passado dá-se através de um personagem histórico, sim, mas de maior sentido para uma história restrita, a literária. Com Machado de Assis é arrastada sua criação mais popular, Capitu, aliás, a protagonista do romance. O fato é que da menina de "olhos oblíquos e dissimulados" ou da mulher dos "olhos de ressaca" pouco resta. A atitude da obra já se anuncia no tratamento parodístico em relação ao original: "Diante daquelas palavras, o olho esquerdo de Capitu se encheu de ironia. O direito, de deboche.” (p. 41), ou então,

Mais tarde, Capitu estava sentada à mesa quando a empregada trouxe um sanduíche de atum. A moça rejeitou. Ela adorava os olhos de atum. Não iria comer carne do peixe que tinha os olhos mais lindos que já vira. (p. 43)

2 HUTCHEON, Linda. Uma teoria da paródia. Ensinamentos das formas de arte do século XX. Lisboa: Edições 70, 1989. p. 11.

3 HUCHETON, Linda. Poética do pós-modernismo: história, teoria e ficção. Rio de Janeiro: Imago, 1991.

4 MENTON, Seymour. La nueva novela histórica de la América Latina. 19791992. México: Fondo de Cultura Económica, 1993.

5 Florianópolis: Paralelo 27, 1993. 
Nos anos 90 do século XX, ela veste-se à moda Sula Miranda, é negra e vive em Blumenau. Aliás, a narrativa dispensa qualquer tentativa de verossimilhança, contrariamente aos recursos utilizados em outras criações, que ora se aproveitam do cenário oitocentista, ora se valem do discurso post-mortem. Dito de outra maneira, é a própria verossimilhança ficcional que se coloca em xeque. Capitu, simplesmente cansada da vida rédea curta que levava, evade-se daquele cenário em busca de outro que lhe dê autonomia - "linguagem é poder", lembra sempre o narrador. A euforia da moça por plena liberdade é, no entanto, cerceada de forma dissimulada pelas limitadas opções impostas pelo domínio da indústria cultural, que se revelam na ironia: "Realmente, havia muito o que se ver nos anos noventa" (p. 18).

A escolha por Machado, por sua vez, faz emergir outros significados. Se Capitu se rende ao fascínio da cultura massificada, Machado ainda é, e cada vez mais, o representante mais valoroso da literatura nacional, o ícone da literatura brasileira. Temos, assim, resenhados os dois pólos com os quais o romance visa a dialogar: a cultura de massa e a literatura de proposta. ${ }^{6}$

\section{Cultura de massa - variações sem mudança}

A denúncia da perda das raízes históricas e populares em favor da instauração de uma cultura forjada para atender a critérios econômicos inicia já pelo cenário da narrativa, Blumenau. $\mathrm{O}$ mito europeu erigido camufla tanto a herança negra como a autêntica raiz européia, transformando-se em pastiche:

Esta cidade já foi negra. Tão negra, como a negritude da louca Bertília, do vereador Badias, do Príncipe Negro (...) Esta cidade também já foi alemã, italiana. Com alemães e italianos as enchentes anuais perderam leveza e novidade. Ganharam angústia. O enxaimel foi despejado da riqueza de detalhes estéticos que abrigava e virou simulacro empobrecido da nostalgia. (p. 10)

6 PAES, José Paulo. Por uma literatura de entretenimento (ou $\mathrm{O}$ mordomo não é o único culpado). In: A aventura literária. São Paulo: Cia. das Letras, 1990. 
A agressividade da colonização alemã é recuperada através de narrativas populares que procuram justificar o extermínio de índios e negros. A festividade mais popular da região, a Oktoberfest, também não foge à mira. As enchentes anuais transformaram-se na possibilidade de uma arrecadação segura a cada ano, evocando assim o mito de Sísifo.

Também a sobrevivência da protagonista deve passar pela descaracterização:

As mulheres usavam o repetitivo jeans SM, o chapéu arreado ou cobrindo as cabeças, a faixa ao redor da testa, a bota. Tudo Pink. Eram clones da cantora sertaneja Sula Miranda e pareciam felizes na condição de simulacros. (p. 33)

Pequenas variações não escamoteiam a mesmice predominante. A superficialidade evidencia-se tanto nas personagens como na trama telenovelesca. As citações comportam desde Madona, Mae West, Sílvio Santos, Hebe Camargo até as bonecas Barbi, garantindo o lugar para o Kitsch e para o grotesco. O que conta afinal é o império das imagens, com sua velocidade e voracidade: “...a solução seria desejar a cena ideal, a próxima” (p. 40).

O diálogo estabelecido com a cultura de massa abre espaço também para as formas escritas através da incorporação de subgêneros ficcionais, como é o caso do policial e da ficção científica.

A trama pseudo-policial constrói-se através de um duplo enredo para os quais não se apresentam soluções. O primeiro detém-se na perseguição de que Capitu é vítima ao longo da obra. O modelo do perseguidor é, no entanto, desconstruído por uma personagem desajeitada. Ao que tudo leva a crer, tratase de Bento Santiago que, ainda não liberto dos ciúmes, não descura dos passos da infiel esposa. A segunda linha do enredo enfoca o roubo do Livro de Borg, sob a guarda de Capitu. Para resolver o enigma é convocado o jogador de basquete Magic Johnson, atual parceiro de Sherlock Holmes. O modelo detetivesco também é subvertido, não só pela personagem como pelo seu método pouco ortodoxo de investigação. Haveria relação entre os dois casos? Pouco se dá a saber; a trama é tecida sobretudo por imagens fragmentárias como requer o trato pós-moderno. 
No que diz respeito à ficção científica, os flashes são ainda mais acidentais, como a evocação à máquina do tempo para o salto de Capitu entre as histórias de que participa ou a reminiscência dos enlatados Jeannie é um gênio ou $A$ mulher maravilha, nas transfigurações da protagonista. Também neste ponto, percebe-se a subversão ao modelo parodiado: "Paramentação completa, o ritual se completava com a cheirada de meia grama de cocaína" (p. 55).

A literatura de auto-ajuda, que já há algum tempo vem recebendo um tratamento especial do mercado editorial, faz sentir também seu eco através de recortes ("se pelo menos não vivêssemos tentando ser felizes, até que poderíamos nos divertir bastante", p. 31) ou nas referências ao ghost-writer. Com presença mais demarcada no romance colocam-se os periódicos de faits divers. Cada capítulo é encabeçado por textos apócrifos, mas nem por isso menos verossímeis, da Isto $e ́$ e da Interview, que através do disperso vão construindo um enredo paralelo.

O efeito que se obtém é o da problematização da sociedade de consumo. A sua presença e efeito não podem ser ignorados. Daí que a literatura a incorpore em seu discurso, resultando o que Costa Lima denominou "a literatura como risco". Como risco porque "para ser eficaz, a crítica à sociedade de mercado há de passar pelo mercado". ${ }^{7}$ Ou seja, o destino de uma obra que intencionalmente achata seus personagens, seu enredo e sua linguagem pode vir a ser o mesmo daquela que ela pretende parodiar.

\section{Literatura de proposta - Para quem?}

Como os demais personagens, Machado de Assis não sai com as cores mais fortalecidas. Destacam-se os aspectos mais novelescos de sua trajetória, a questão racial e a epilepsia, não se furtando a criar com o conjunto a idéia do "mostrengo", reiterada diversas vezes. A representação machadiana toca o grotesco, em especial na cena em que Machado é surpreendido por um ataque epilético em meio à transa com Capitu.

O que se coloca em discussão com a personagem é a monumentalização do escritor na cultura brasileira. Aliás, a idéia de construção é dada pela oposição freqüente entre o Machadinho, como Capitu o chama, e o Machadão, evocando o medalhão, forma preferida por Bentinho. Para questionar esse sólido edifício,

7 A literatura como risco. Folha de São Paulo, 16 abr. 2000. Caderno Mais. 
faz-se necessário dialogar com seus construtores, ou seja, a crítica literária e, particularmente, com a crítica biográfica devido à sua feição caricata em nossos dias. Caricata, diga-se de passagem, para o meio acadêmico, porque a sua utilização ainda se mostra vitalizada no ensino e nos meios de comunicação em geral. A figura de Machado é recortada pelo ridículo. Além da doença genética e da condição de "mulatinho", a interpretação de Araripe Junior ${ }^{8}$ de que lhe faltava um "odor de femina" engrossa o estereótipo. O retraimento do escritor, fechado num mundo de livros, também é repassado.

Machado ainda vincula-se à Academia, não a Brasileira de Letras, mas ao Departamento de Literatura Brasileira da Universidade de Blumenau. E é aí que se insere a crítica mais contundente, ou seja, o divórcio entre a comunidade acadêmica e a sociedade em geral. O campus universitário divide-se entre a prática inócua do conhecimento, realizado de segunda à quarta-feira, e a Babel do comércio que invade as suas áreas livres:

A versatilidade da universidade se adaptava magnificamente às duas atividades antagônicas. Saber e economia informal. Aulas e muambas eletrônicas fáceis. Capitu constatou que no campus da universidade de Blumenau o irreconciliável se reconciliava. Muito dólar, a moeda paraguaia. Pouca universidade. (p. 15)

De fato, o que se expressa é a constatação de um mundo em que Machado de Assis, ícone da literatura de proposta, não existe. Não existe fora do país, como o comprova a fala de Michael Douglas: "Who the hell is that Dom Casmurro?" (p. 71). Também nada significa para a empregada de Capitu ou para os pivetes com quem a protagonista trava contato. Machado serve apenas a uma comunidade acadêmica, ou seja, a um universo isolado.

Talvez seja também por isso que pouco resta dele ou da sua obra em Enquanto isso em Dom Casmurro. E é nesse sentido que o discurso midiático, entremeado na narrativa, ganha sentido. Ao questionar o abismo entre a literatura de proposta e os bens da cultura de massa, ele lança a provocação: que diferença há de fato entre a especulação crítica acerca do adultério de Capitu e o suposto

8 Apud MAGALHÃES JÚNIOR, Raimundo. Vida e obra de Machado de Assis. Rio de Janeiro: Civilização Brasileira, 1981. v. 3. p. 196. 
romance entre Sula Miranda e Sílvio Santos, veiculado pelas revistas? Será que ambos não passam de um fofoca editorial com intenções comerciais? Pois, embora isolada como meio de intervenção social, a comunidade acadêmica também não se alheia às leis do mercado:

Machado de Assis ponderou que alterar o romance Dom Casmurro àquela altura do campeonato seria uma empreitada impossível. Os leitores já tinham se identificado e aceito a história. Os críticos teriam que refazer as bobagens que tinham escrito. Teriam que criar outras. As editoras teriam que gastar milhões em direitos autorais, impressão e divulgação nas mídias. (p. 26)

A representação machadiana enfoca ainda o realismo, lido como sinônimo de velharia, antiqualha. Talvez a alusão não seja tanto em relação ao estilo de época, mas sim em razão do ceticismo em qualquer forma de representação que se queira verossímil. A consciência do caráter construtivo de todos os discursos relegou-nos à experiência da ausência de fé em qualquer realidade palpável. Ou no dizer de Jean Baudrillard:

A própria possibilidade de representação do mundo seria uma ilusão, e a "realidade", tal como a entendemos habitualmente, uma impostura: no mundo transformado em "tela total", os signos se esvaziam de sentido. É necessário esquecer a luz das estrelas mortas. A incerteza é a nova regra. ${ }^{9}$

9 O Globo, 18 maio 2002. Prosa \& verso, p. 3. 


\section{Pós-Modernidade - Espaço de confluências}

O espaço pós-moderno assume-se na confluência desses pólos contrastantes. Cultura erudita e cultura de massa dividem o mesmo espaço com vistas a questionar a distância entre eles. As citações a Derrida, John Barth, Woody Allen operam no mesmo nível que aquelas a Madona, Simon and Garfunkel, Mae West. Como pondera Linda Hutcheon:

...a crescente uniformização da cultura de massa é uma das forças totalizantes que o pós-modernismo existe para desafiar. Desafiar, mas não negar. Mas ele realmente busca afirmar a diferença, e não a identidade homogênea. ${ }^{10}$

E mais, "tudo o que ela [cultura pós-moderna] pode fazer é questionar a partir de dentro", ${ }_{11}$ ou seja, de seu próprio interior.

O resultado, contudo, não se revela animador. Os universos ficcionais mais desbaratados podem se tocar, mas dificilmente interagem. Exemplo disto é a relação frustrada entre Capitu e Michael Douglas. Noutro pólo, poderíamos ler a intervenção de Capitu na trama da obra $A$ cor púrpura, modificando-lhe o final. $\mathrm{O}$ efeito, no entanto, dá-se pelo oposto, apontando para a inverossimilhança. Quer-se dizer, o deslocamento do referente ficcional despotencializa o ficcional ao se desnudar como tal. O mesmo, aliás, já se verificara quanto à remissão ao procedimento da ficção científica. A representação não convence e objetiva isso mesmo, delatar o universo de construções em que vivemos. As notícias da enchente em Blumenau dissolvem-se no próximo capítulo da telenovela (p. 95). Talvez, estejamos na presença do que Costa Lima descreve como a ficcionalização que acaba por vetar o objeto ficcional. Ou seja, a ficcionalização da realidade concorre para a ineficácia da ficção como forma desestabilizadora. ${ }^{12}$

A perda do sentido expõe-se na evocação a Walter Benjamin sobre a perda da aura e na reflexão do narrador:

10 Poética do pós-modernismo..., p. 22.

11 Ibid., p. 15.

12 O fingidor e o censor no Ancien Régime, no Iluminismo e hoje. Rio de Janeiro: Forense Universitária, 1988. p. 357-371. 
Não se podia mais confiar nos velhos símbolos. Decadentes metáforas, signos empobrecidos. Todos haviam perdido o valor. Nem conseguiam esconder algum sentido por trás de si mesmos. Tudo era visível, superficial. Tudo estava ao toque da mão. Na superfície se alojava o sentido das coisas. Os símbolos perderam a profundidade. Era a simbólica economia dos signos que tanto agrada a Baudrillard. (p. 78)

O cansaço revela-se nas clonagens que apenas aumentam a sensação de solidão. Até mesmo o desejo se perde:

Em Dom Casmurro a realidade podia tudo. Em Enquanto Isso

Em Dom Casmurro a linguagem criava a realidade. Criava até o desejo que propiciava a realidade desejada. (p. 79)

Apocalíptico? Nem tanto. O tom é algo pessimista: a inevitabilidade da hegemonia da indústria cultural e a ineficiência da cultura de proposta. Tom quebrado, no último capítulo, pela exaltação da bandeira dos sem-voz reunidos num jantar comemorativo. Infelizmente! Não aprendeu Endoença as lições do mestre: não há de se fiar em nada e desconfiar de tudo? Ou melhor: quem disse isto? Machado ou a sua crítica? O que nos comprova que a literatura é sempre um risco.

\section{Retrato às avessas}

Ao convocar a crítica machadiana, damo-nos conta de que nem tudo é tão simples no reino da ficção. Se, a princípio, personagens e enredo primam pelo estereótipo, ironicamente, as questões levantadas pelo romance reduplicam as palavras da crítica que se debruçou sobre Machado. Lembre-se que essa crítica contempla um universo ilimitado de possibilidades. Nenhuma tendência parece ter prescindido desse objeto: crítica impressionista, biográfica, estilística, 
sociológica, histórica, marxista, chegando até mesmo aos defensores da atitude pós-moderna em Machado.

Aos olhos do leitor contemporâneo, a tarefa de definir o grau de interpenetração da obra e de suas leituras parece impossível e até mesmo contraproducente. $\mathrm{O}$ que nos obriga a ler Machado juntamente com a sua enciclopédia e, simultaneamente, nos leva ao assombro com o grau de criatividade de uma crítica que consegue construir a sua obra. O que acontece, então, se a essa enciclopédia adicionamos ainda a criação literária? Compõe-se, desse modo, um emaranhado de textos em que se verifica o espelhamento de prática e de teoria, não se podendo precisar até que ponto uma se reflete na outra; um abismo de referências.

É nesse sentido que vários procedimentos de Enquanto isso... reduplicam a leitura machadiana. $\mathrm{O}$ quadro pessimista da sociedade blumenauense, por exemplo, ecoa o ceticismo na retratação, também às avessas, da vida no Segundo Império; a quebra da verossimilhança, o estranhamento e a instabilidade do narrador realizam-se de modo diverso, mas apontam para a mesma questão. Que dizer então da leitura sociológica contemporânea? Subvertida a relação racial através da patroa negra e da empregada branca, ainda assim seculariza-se a ideologia do favor e da dependência. Ou seja, retrato que sai às avessas, que se impõe não obstante a denúncia e que assinala a feição ensaística da ficção dos anos 80, conforme Flora Süssekind:

Tanto a linguagem crítica tem se encaminhado para uma dicção mais ensaística, quanto a prosa de ficção tem se deixado contaminar pelo aspecto reflexivo, pela capacidade de se pôr à prova, do ensaio. ${ }^{13}$

13 Ficção 80: dobradiças e vitrines. In: Papéis colados. Rio de Janeiro: Ed. UFRJ, 1993. p. 247. 


\title{
RESUMO
}

Leitura de Enquanto isso em Dom Casmurro, do professor catarinense José Endoença Martins, observando como a tentativa de atualização de Machado no transplante para outro tempo e outro espaço busca a subversão, mas resulta em reduplicação.

Palavras-chave: ficção histórica, metaficção, José Endoenças Martins.

\begin{abstract}
A reading of Enquanto isso em Dom Casmurro, by José Endoença Martins, attending to the fact that an updating of Machado's world transported to another time and space tries a subversion, but results in reduplication.

Key-words: historical fiction, metafiction, José Endoenças Martins.
\end{abstract}

\section{REFERÊNCIAS}

BAUDRILLARD, Jean. Mal-estar na representação. $O$ Globo, 18 maio 2002. Prosa \& verso, p. 3.

HUTCHEON, Linda. Uma teoria da paródia. Ensinamentos das formas de arte do século XX. Lisboa: Edições 70, 1989.

.Poética do pós-modernismo: história, teoria e ficção. Rio de Janeiro: Imago, 1991.

LIMA, Luiz Costa. O fingidor e o censor no Ancien Régime, no Iluminismo e hoje. Rio de Janeiro: Forense Universitária, 1988.

. A literatura como risco. Folha de São Paulo, 16 abr. 2000. Caderno Mais.

MAGALHÃES JÚNIOR, Raimundo. Vida e obra de Machado de Assis. Rio de Janeiro: Civilização Brasileira, 1981. v. 3.

MARTINS, José Endoença. Enquanto isso em Dom Casmurro. Florianópolis: Paralelo 27, 1993.

MENTON, Seymour. La nueva novela histórica de la América Latina. 1979-1992. México: Fondo de Cultura Económica, 1993. 
NASCIMENTO, N. de A. Retratos e simulacros machadianos:...

PAES, José Paulo. Por uma literatura de entretenimento (ou O mordomo não é o único culpado). In: . A aventura literária. São Paulo: Cia. das Letras, 1990.

PERRONE-MOISÉS, Leyla. Texto, crítica e escritura. São Paulo: Ática, 1978.

SÜSSEKIND, Flora. Ficção 80: dobradiças e vitrines. In: . Papéis colados. Rio de Janeiro: Ed. da UFRJ, 1993. 